\title{
Substituting brown rice for white rice on diabetes risk factors in India: a randomised controlled trial
}

\author{
V. S. Malik ${ }^{1 *}$, V. Sudha ${ }^{2}$, N. M. Wedick ${ }^{1}$, M. RamyaBai ${ }^{2}$, P. Vijayalakshmi ${ }^{2}$, N. Lakshmipriya ${ }^{2}$, R. Gayathri ${ }^{2}$, \\ A. Kokila ${ }^{2}$, C. Jones ${ }^{3}$, B. Hong ${ }^{4}$, R. Li ${ }^{4}$, K. Krishnaswamy ${ }^{2}$, R. M. Anjana ${ }^{2}$, D. Spiegelman ${ }^{1,4,5,6}$, \\ W. C. Willett ${ }^{1,5}$, F. B. Hu ${ }^{1,5}$ and V. Mohan ${ }^{2}$ \\ ${ }^{1}$ Department of Nutrition, Harvard T.H. Chan School of Public Health, Boston, MA, USA \\ ${ }^{2}$ Madras Diabetes Research Foundation E Dr. Mohan's Diabetes Specialities Centre, Gopalapuram, Chennai, India \\ ${ }^{3}$ School of Medicine, Tufts University, Boston, MA, USA \\ ${ }^{4}$ Department of Biostatistics, Harvard T.H. Chan School of Public Health, Boston, MA, USA \\ ${ }^{5}$ Department of Epidemiology, Harvard T.H. Chan School of Public Health, Boston, MA, USA \\ ${ }^{6}$ Department of Biostatistics, Yale School of Public Health, New Haven, CT, USA
}

(Submitted 5 December 2018 - Final revision received 18 March 2019 - Accepted 20 March 2019 - First published online 21 June 2019)

\begin{abstract}
India has the second largest number of people with type 2 diabetes (T2D) globally. Epidemiological evidence indicates that consumption of white rice is positively associated with T2D risk, while intake of brown rice is inversely associated. Thus, we explored the effect of substituting brown rice for white rice on T2D risk factors among adults in urban South India. A total of 166 overweight $\left(\mathrm{BMI} \geq 23 \mathrm{~kg} / \mathrm{m}^{2}\right) \mathrm{adults}$ aged 25-65 years were enrolled in a randomised cross-over trial in Chennai, India. Interventions were a parboiled brown rice or white rice regimen providing two ad libitum meals/d, $6 \mathrm{~d}$ /week for 3 months with a 2-week washout period. Primary outcomes were blood glucose, insulin, glycosylated $\mathrm{Hb}(\mathrm{HbA1c}$ ), insulin resistance (homeostasis model assessment of insulin resistance) and lipids. High-sensitivity C-reactive protein (hs-CRP) was a secondary outcome. We did not observe significant between-group differences for primary outcomes among all participants. However, a significant reduction in HbA1c was observed in the brown rice group among participants with the metabolic syndrome $(-0.18$ (sE 0.08$) \%)$ relative to those without the metabolic syndrome $(0.05$ (sE 0.05$) \%)(P$-for-heterogeneity $=0.02)$. Improvements in HbA1c, total and LDL-cholesterol were observed in the brown rice group among participants with a BMI $\geq 25 \mathrm{~kg} / \mathrm{m}^{2}$ compared with those with a $\mathrm{BMI}<25 \mathrm{~kg} / \mathrm{m}^{2}$ ( $P$-for-heterogeneity $<0.05$ ). We observed a smaller increase in hs-CRP in the brown (0.03 (sD $\left.\left.2 \cdot 12\right) \mathrm{mg} / \mathrm{l}\right) \mathrm{compared}$ with white rice group $(0.63(\mathrm{sD} 2.35) \mathrm{mg} / \mathrm{l})(P=0.04)$. In conclusion, substituting brown rice for white rice showed a potential benefit on HbA1c among participants with the metabolic syndrome and an elevated BMI. A small benefit on inflammation was also observed.
\end{abstract}

Key words: Brown rice: White rice: Diabetes risk factors: Metabolic syndrome: Glycaemic index: Randomised controlled trials: Urban India

Type 2 diabetes (T2D) has become a major contributor to the global disease burden. At least 425 million people worldwide have T2D, and an increase to 629 million is expected by the year $2045^{(1)}$. India is at the forefront of the T2D epidemic, ranking second among countries with the greatest number of people living with the condition globally ${ }^{(1)}$. A recent nationwide T2D survey found high prevalence rates among low socio-economic groups in urban as well as rural areas in India, where two-thirds of the population resides ${ }^{(2)}$. The costs related to treatment of T2D are of great concern to public health and the economy of India given the limited healthcare resources to manage the dramatic rise in prevalence alongside coexisting burdens of undernutrition and communicable diseases ${ }^{(3)}$. Thus, effective, affordable and sustainable strategies for T2D prevention are needed to reduce early death and disabilities, contain climbing healthcare and societal costs, and improve overall quality of life.

In urban south India, nearly half of daily energy intake comes from refined grains, with white rice constituting $>75 \%$ of refined grain intake ${ }^{(4)}$. Compared with brown rice, a whole grain, white rice contains little dietary fibre, $\mathrm{Mg}$, and other phytochemicals, all of which may reduce risk for T2D. In epidemiological studies, consumption of white rice has been associated with increased

Abbreviations: GI, glycaemic index; GL, glycaemic load; HbA1c, glycosylated Hb; HOMA-IR, homeostasis model assessment of insulin resistance; hs-CRP, high-sensitivity C-reactive protein; T2D, type 2 diabetes.

* Corresponding author: Vasanti S. Malik, email vmalik@hsph.harvard.edu 
risk for $\mathrm{T} 2 \mathrm{D}^{(5)}$ and in a pooled analysis of three large US cohorts substituting $50 \mathrm{~g} / \mathrm{d}$ of brown rice for white rice was associated with a $16 \%$ lower risk of $\mathrm{T} 2 \mathrm{D}^{(6)}$. In our previous short-term trial using continuous glucose monitoring, replacing white rice with brown rice significantly reduced the 24 -h glycaemic response and fasting insulinaemic response among overweight South Indians ${ }^{(7)}$. These findings, combined with our previous qualitative studies in a similar South Indian population, which identified strategies to increase acceptability of brown rice and demonstrated willingness to participate in a brown rice intervention, provided the rationale for the present trial ${ }^{(8-11)}$. Here we aimed to investigate the effect of substituting brown rice for white rice on metabolic markers of T2D risk among adults in urban South India.

\section{Methods}

\section{Setting}

This study was conducted at a large tertiary care centre for diabetes in Chennai, a major city in South India. The study protocol was approved by the Institutional Review Boards of both the Harvard T.H. Chan School of Public Health and Madras Diabetes Research Foundation and registered with ClinicalTrials.gov (NCT01814735)

\section{Study population}

Participants were recruited from MDRF as well as from surrounding offices through advertisements. Staff from these facilities and their relatives were invited to participate in this study. Eligibility criteria were age $25-65$ years; $\mathrm{BMI} \geq 23 \mathrm{~kg} / \mathrm{m}^{2}$ and a habitual consumer of rice. Two additional eligibility criteria specifying a daily rice consumption of $>200 \mathrm{~g}$ per $\mathrm{d}$ and having an elevated waist circumference were dropped prior to recruitment for feasibility and logistical reasons. It was also assumed that most South Asians with an elevated BMI would also have central adiposity. Exclusion criteria included having a fasting blood glucose $\geq 126 \mathrm{mg} / \mathrm{dl}(7.0 \mathrm{mmol} / \mathrm{l})$ or postprandial blood glucose $\geq 200 \mathrm{mg} / \mathrm{dl}(11.1 \mathrm{mmol} / \mathrm{l})$; a diagnosed chronic disease that may affect the study outcomes or that would make participation potentially harmful, including diabetes, severe kidney disease, CVD (coronary artery disease, peripheral vascular disease), history of stroke, cancer, severe psychological disorders (schizophrenia, dementia), or hypothyroidism; being pregnant or lactating; and plans to relocate in the next year. At the screening visit, height and weight were measured, and a questionnaire was administered to assess habitual rice intake, medical history, demographics and lifestyle factors. A total of 352 participants were screened of which 171 were eligible and willing to participate (Fig. 1).

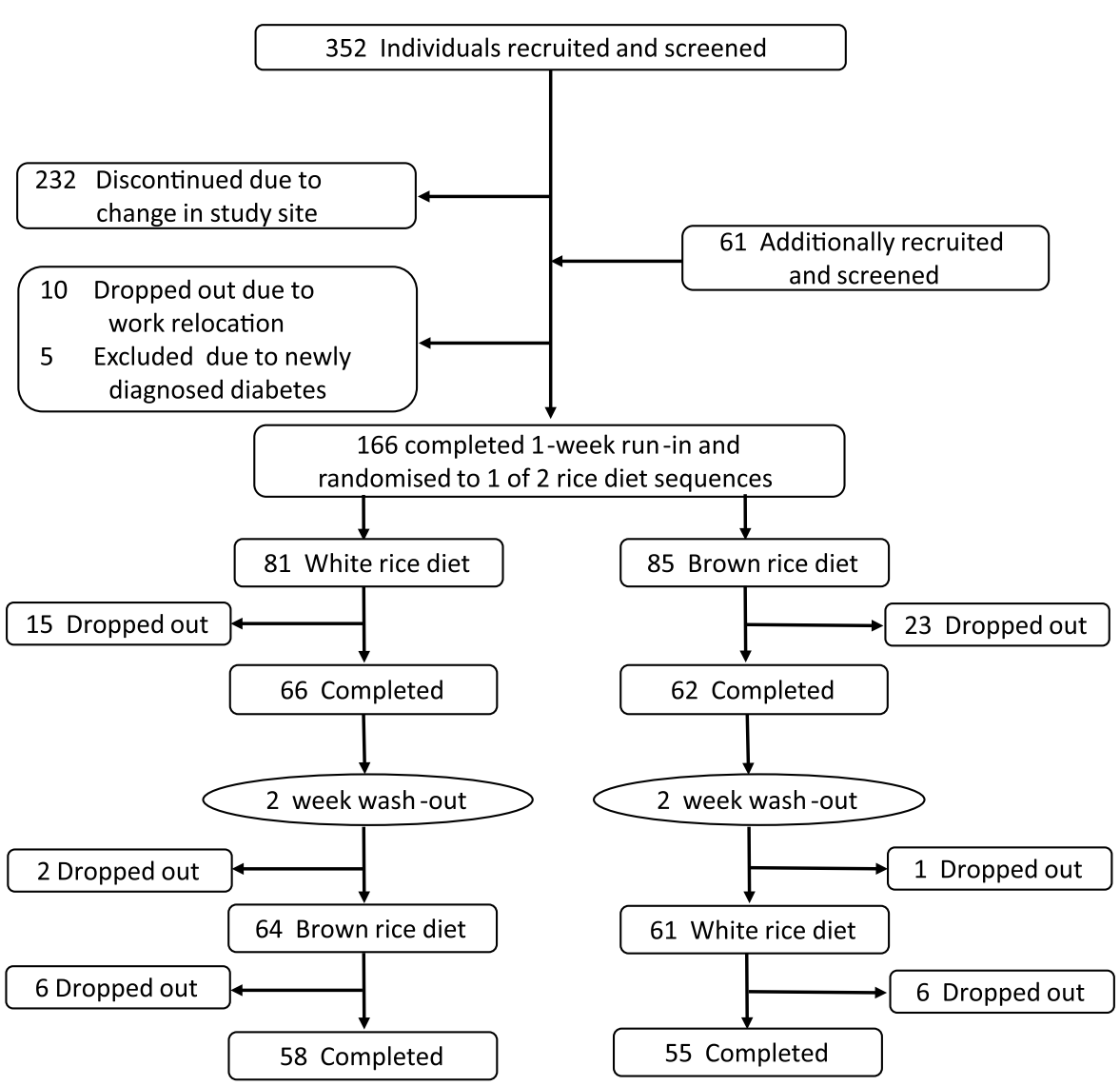

Fig. 1. Participant screening, enrollment and follow-up. Inclusion criteria: age $25-65$ years; $B M I \geq 23 \mathrm{~kg} / \mathrm{m}^{2}$ and a habitual consumer of rice. Exclusion criteria: fasting blood glucose $\geq 126 \mathrm{mg} / \mathrm{dl}(7.0 \mathrm{mmol} / \mathrm{l})$ or postprandial blood glucose $\geq 200 \mathrm{mg} / \mathrm{dl}(11.1 \mathrm{mmol} / \mathrm{l})$; diagnosed chronic disease that may affect study outcomes or would make participation potentially harmful, including diabetes, severe kidney disease, CVD, history of stroke, cancer, severe psychological disorders (schizophrenia, dementia), or hypothyroidism; being pregnant or lactating; and plans to relocate in the next year. At the end of the study, 121 participants had completed the white rice diet and 120 participants had completed the brown rice diet. 
These participants underwent an oral glucose tolerance test to determine existing and newly diagnosed T2D. Five newly diagnosed cases were identified and these participants were subsequently excluded, leaving 166 participants for inclusion in the study. All participants were given full details about the trial, after which each gave informed written consent.

\section{Study design}

This study was a non-blinded randomised cross-over dietary intervention trial, consisting of a parboiled brown rice or a white rice regimen, each providing two ad libitum meals/d (breakfast and lunch), $6 \mathrm{~d}$ /week for 3 months with a 2-week washout period. Prior to randomisation, a 1-week run-in phase was conducted. Randomisation was performed using computer-generated random numbers with an equal treatment allocation ratio. A stratification factor for sex was included in the randomisation scheme. Intervention meals were administered and consumed at the on-site dining facility. To monitor whether participants received the correct test foods according to randomisation, they were given photo identification badges with colour-coded ribbons when they entered the dining area. Participants were also requested to sign a register kept at the dining area before picking up their meal, which was used to count their number of participatory days in the intervention. Study staff had direct contact with participants during daily visits to the centre, and this helped to provide motivation to continue in the study. Participants who dropped-out were contacted to ascertain their reason for discontinuation. Compliance was assessed by direct observation of daily participation, number of meals consumed, and serving size of foods consumed as well as monthly 24-h diet recalls.

\section{Intervention diets}

A total of nine white rice-based and nine corresponding brown rice-based recipes were developed and standardised for the trial, based on our previous work ${ }^{(12,13)}$. A description of the intervention menu and individual rice-based dishes have been previously reported $^{(12)}$. We used the same strain of rice (BPT 5204) which we used in our previous proof-of-concept continuous glucose monitoring study ${ }^{(7)}$. Non-parboiled white rice is the most commonly consumed type of rice across India, thus we selected it as the control diet in this trial. Because brown rice was not available in the market, our team worked with a local rice miller to produce brown rice from the same rice strain (BPT 5204) that was parboiled for the intervention. Milling was coordinated to produce batches of brown and white rice from a single strain to minimise intra-varietal variations due to season and other environmental factors. Brown rice can remain shelf stable for a longer time when parboiled since parboiling arrests lipolytic enzyme activity reducing the chance of rancidity due to the high fat content in rice bran. The glycaemic index (GI) values of individual intervention dishes have been estimated and reported previously ${ }^{(12)}$. The estimated GI of the white rice-based dishes ranged from 69.4 to 84 . For the brown rice-based dishes, GI values ranged from $50 \cdot 2$ to $59 \cdot 7$. Based on these values, there was an approximate difference in GI of $25-30 \%$ between intervention foods. Meals were prepared in accordance with Hazard Analysis and Critical Control Point (HACCP) regulations and dietitians regularly monitored cooking practices, facilities, storage and dispatch of food.

\section{Measurements}

A detailed description of study measurements has been previously reported $^{(12)}$. The primary outcomes for this intervention were fasting plasma glucose, insulin, glycosylated $\mathrm{Hb}$ (HbA1c) and lipids (total cholesterol, TAG, LDL-cholesterol and HDLcholesterol). High-sensitivity C-reactive protein (hs-CRP) was assessed as a secondary endpoint as the intervention may impact inflammation in addition to biomarkers of glycaemic control and lipids. Blood samples were obtained at baseline and at the end of each intervention and analysed at the National Accreditation Board for Testing and Calibration Laboratories and the College of American Pathologists accredited central laboratory at Dr. Mohan's Diabetes Specialities Centre in Chennai, India. Fasting blood (after 10-12 h fast) was obtained by an experienced phlebotomist. Samples were immediately centrifuged, aliquoted, transported on dry ice and stored at $-80^{\circ} \mathrm{C}$. All assays were performed at the end of the study to control for assay variation and laboratory technicians were blinded to participant study group assignment. Plasma glucose (glucose oxidase peroxidase method), serum cholesterol (cholesterol oxidase-peroxidase-4-aminophenazone method), serum TAG (glycerol phosphate oxidase-peroxidase4-aminophenazone method) and HDL-cholesterol (direct method with polyethylene glycol pretreated enzymes) were measured using a Hitachi 912 Autoanalyzer (Roche Diagnostics, GmbH) and utilising kits supplied by Boehringer Mannheim. LDL-cholesterol was calculated using the Friedewald formula in participants with TAG $\leq 400 \mathrm{mg} / \mathrm{dl}$ $(4.5 \mathrm{mmol} / \mathrm{l})$. Serum insulin concentration was estimated using Dako kits; HbA1c was measured using a Variant machine (Biorad). Plasma concentrations of hs-CRP were measured by a highly sensitive nephelometric assay using a monoclonal antibody to CRP coated on polystyrene beads (Dade Behring). Insulin resistance was estimated from the homeostasis model assessment of insulin resistance (HOMA-IR) by the following formula: (fasting insulin $(\mathrm{mU} / \mathrm{ml})) \times(\text { fasting glucose }(\mathrm{mmol} / \mathrm{l}) / 22 \cdot 5)^{(14)}$.

Anthropometric measurements were collected at baseline and monthly at clinic visits through the end of follow-up. Body weight $(\mathrm{kg})$, height $(\mathrm{cm})$ and waist circumference $(\mathrm{cm}$, measurement taken at the end of expiration) were measured using standardised methods. BMI was calculated as weight (kg) divided by height $\left(\mathrm{m}^{2}\right)$. Overweight $\left(\geq 23 \mathrm{~kg} / \mathrm{m}^{2}\right)$ and obesity $\left(\geq 25 \mathrm{~kg} / \mathrm{m}^{2}\right)$ were defined according to the Asia Pacific Classification (WHO, 2000) $)^{(15)}$. Percentage body fat was measured using a body composition monitor based on bioelectrical impedance (Salter-Omron, HBF 212). Blood pressure was measured at baseline only using a blood pressure monitor (Omron, Hem7101). Diet was assessed at baseline using a validated interviewer-administered food frequency questionnaire evaluating usual consumption habits over the past year, and with monthly 24-h diet recalls during follow-up. Satiety (assessed with a seven-point Likert scale) and adverse effects of intervention meals were also ascertained monthly. Physical activity was assessed at baseline via the MDRF - Physical Activity questionnaire (MPAC), a valid and reliable interviewer-administered 
tool $^{(16)}$ and smoking and other lifestyle and sociodemographic factors were assessed on the screening questionnaire.

\section{Statistical methods}

A sample of 166 participants was randomised for the present study to provide a power of $80 \%$ for the cross-over design to detect a percentage change between 2 (fasting glucose) to 14 (fasting insulin and HOMA) in the intervention group, allowing for $15 \%$ drop-out, with a type 1 error rate of 0.05 , an assumed intra-class correlation of 0.85 and assuming no change in the intervention group. Intra-class correlations for baseline biochemical and clinical characteristics were calculated to assess consistency across study periods. To calculate point and interval estimates of effect, mean and standard deviation baseline and end of follow-up values of each biomarker were calculated for each intervention group, along with their respective change (and standard deviation) from baseline. To test the statistical differences in changes from baseline between the brown and white rice intervention arms in biomarkers, body measurements, and dietary intake, mixed models for repeated measurements were used with the robust variance and an exchangeable working correlation matrix ${ }^{(17)}$. Given sufficient sample size, this approach provides confidence intervals and $P$ values that are guaranteed to be valid regardless of the distribution of the dependent variables ${ }^{(17)}$. An advantage of this approach is that the results can be reported in the measured scale of interest. Sub-group analysis by sex, age, physical activity, baseline anthropometric and biochemical measurements and opinion about whether brown rice was considered healthy were conducted along with corresponding tests for heterogeneity using the robust score test. To test the robustness of our results, various sensitivity analyses were conducted including adjusting the analysis for change in BMI and testing for a potential carry-over effect by creating an interaction term between study period and intervention group. We also evaluated between-group differences using end of follow-up measurements only as a potential strategy to improve statistical efficiency and a multiple outcome $1 \mathrm{df}$ test that simultaneously evaluated primary and secondary outcomes as one composite variable ${ }^{(18)}$. Between-group differences in satiety of intervention foods were evaluated using the Wilcoxon signed-rank test. Statistical tests were two-sided and performed using SAS version 9.2 for UNIX.

\section{Results}

During the first period of the study, fifteen participants dropped out of the white rice group and twenty-five dropped out of the brown rice group (Fig. 1). Prior to crossing over to the other diet period, an additional two participants discontinued from the white rice group and one participant discontinued from the brown rice group. During the second diet period, six participants discontinued from each group leaving 121 and 120 participants available for analysis from the white rice and brown rice periods, respectively, with an overall dropout rate of $33 \%$. The majority of dropouts were due to job change $(30 \%)$ or personal reasons $(34 \%)$.

\section{Baseline characteristics of study population}

Men comprised $55 \%$ of the study population and participants had a mean age of 37 years and BMI of $28.1 \mathrm{~kg} / \mathrm{m}^{2}$ at baseline (Table 1). Of the participants, $68 \%$ had pre-diabetes with HbA1c between 5.7 and $6.4 \%$, and $40 \%$ of participants had the metabolic syndrome, defined as having at least three of the five following components: elevated waist circumference ( $\geq 90 \mathrm{~cm}$ for men, $\geq 80 \mathrm{~cm}$ for women); low HDL-cholesterol $(<40 \mathrm{mg} / \mathrm{dl}(1.0 \mathrm{mmol} / \mathrm{l})$ for $\mathrm{men},<50 \mathrm{mg} / \mathrm{dl}(1.3 \mathrm{mmol} / \mathrm{l})$ for women); high TAG ( $\geq 150 \mathrm{mg} / \mathrm{dl} ; 1.7 \mathrm{mmol} / \mathrm{l})$; elevated blood pressure (systolic $\geq 130$ or diastolic $\geq 85 \mathrm{mmHg}$ ) and impaired fasting glucose $(\geq 100 \mathrm{mg} / \mathrm{dl} ; 5 \cdot 6 \mathrm{mmol} / \mathrm{l})$. Participants consumed $59 \%$ of total energy from carbohydrate, $11 \%$ of energy from protein and $29 \%$ of energy from fat. Estimated intake of white and brown rice at baseline was 204 (SD 85.3) and 1.3 (SD 2.8) g per d,

Table 1. Baseline characteristics of participants ( $n$ 166) (Mean values and standard deviations; percentages)

\begin{tabular}{|c|c|c|}
\hline & Mean & SD \\
\hline Age (years) & $37 \cdot 1$ & 9.4 \\
\hline Male (\%) & \multicolumn{2}{|c|}{55} \\
\hline $\mathrm{BMI}\left(\mathrm{kg} / \mathrm{m}^{2}\right)$ & $28 \cdot 1$ & 3.4 \\
\hline Body fat based on BIA (\%) & $32 \cdot 2$ & 8.9 \\
\hline Waist circumference $(\mathrm{cm})$ & $92 \cdot 1$ & 8.7 \\
\hline Engage in moderate or vigorous activity (\%) & \multicolumn{2}{|c|}{11} \\
\hline Fasting blood glucose $(\mathrm{mg} / \mathrm{dll}) \dagger$ & $86 \cdot 6$ & 11.3 \\
\hline Fasting insulin $(\mu \mathrm{l} \mathrm{U} / \mathrm{ml})$ & $12 \cdot 9$ & $8 \cdot 2$ \\
\hline Insulin resistance (HOMA-IR) & $2 \cdot 8$ & $2 \cdot 0$ \\
\hline $\mathrm{HbA} 1 \mathrm{c}(\mathrm{mmol} / \mathrm{mol})$ & 37.6 & 5.7 \\
\hline $\mathrm{HbA1c}(\%)$ & $5 \cdot 6$ & 0.52 \\
\hline $\mathrm{HbA} 1 \mathrm{c} \% \geq 5.6(\%)$ & \multicolumn{2}{|c|}{68} \\
\hline hs-C-reactive protein $(\mathrm{mg} / \mathrm{l})$ & 4.1 & 2.8 \\
\hline Cholesterol $(\mathrm{mg} / \mathrm{dl}) \dagger$ & $177 \cdot 3$ & $34 \cdot 2$ \\
\hline TAG $(\mathrm{mg} / \mathrm{dl}) \dagger$ & $126 \cdot 5$ & 78.5 \\
\hline HDL-cholesterol $(\mathrm{mg} / \mathrm{dl}) \dagger$ & 38.5 & $7 \cdot 1$ \\
\hline LDL-cholesterol $(\mathrm{mg} / \mathrm{dl}) \dagger$ & 114.8 & 30.5 \\
\hline Hypertension (\%) & \multicolumn{2}{|c|}{36} \\
\hline Metabolic syndrome $(\%)^{\star}$ & \multicolumn{2}{|c|}{40} \\
\hline Current smoker (\%) & \multirow{2}{*}{\multicolumn{2}{|c|}{$\begin{array}{l}10 \\
23\end{array}$}} \\
\hline Consume alcohol (\%) & & \\
\hline Energy intake $(\mathrm{kcal}) \dagger$ & 2834 & 823 \\
\hline Carbohydrate (\% energy) & $59 \cdot 1$ & $5 \cdot 2$ \\
\hline Protein (\% energy) & $11 \cdot 3$ & $1 \cdot 3$ \\
\hline Total fat (\% energy) & 28.9 & 4.1 \\
\hline Saturated fat (\% energy) & 9.0 & 1.6 \\
\hline Monounsaturated fat (\% energy) & $8 \cdot 0$ & 1.3 \\
\hline Polyunsaturated fat (\% energy) & $10 \cdot 3$ & 1.9 \\
\hline Glycaemic index & $61 \cdot 2$ & $2 \cdot 9$ \\
\hline Glycaemic load & 224.4 & $65 \cdot 3$ \\
\hline Dietary fibre $(\mathrm{g} / \mathrm{d})$ & 37.5 & 11.9 \\
\hline Refined wheat flour $(\mathrm{g} / \mathrm{d})$ & $45 \cdot 2$ & 39.6 \\
\hline Whole wheat flour $(\mathrm{g} / \mathrm{d})$ & 5.4 & 9.6 \\
\hline Whole millet $(\mathrm{g} / \mathrm{d})$ & 4.2 & 9.1 \\
\hline White rice $(\mathrm{g} / \mathrm{d})$ & $204 \cdot 4$ & $85 \cdot 3$ \\
\hline Brown rice $(\mathrm{g} / \mathrm{d})$ & $1 \cdot 3$ & $2 \cdot 8$ \\
\hline Think that brown rice is healthy (\%) & \multicolumn{2}{|c|}{74} \\
\hline
\end{tabular}

BIA, bioelectrical impedance analysis; HOMA-IR, homeostasis model assessment of insulin resistance; $\mathrm{HbA} 1 \mathrm{c}$, glycosylated $\mathrm{Hb}$.

* The metabolic syndrome is defined as having at least three of the following: elevated waist circumference ( $\geq 90 \mathrm{~cm}$ in men, $\geq 80 \mathrm{~cm}$ in women); low HDL-cholesterol ( $<40$ $\mathrm{mg} / \mathrm{dl}(1.0 \mathrm{mmol} / \mathrm{l})$ in men, $<50 \mathrm{mg} / \mathrm{dl}(1.3 \mathrm{mmol} / \mathrm{l})$ in women); high TAG $(\geq 150 \mathrm{mg} / \mathrm{dl}$; $1.7 \mathrm{mmol} / \mathrm{l}$ ); elevated blood pressure (systolic $\geq 130$ or diastolic $\geq 85 \mathrm{mmHg}$ ) and impaired fasting glucose ( $\geq 100 \mathrm{mg} / \mathrm{dl} ; 5.6 \mathrm{mmol} / \mathrm{l})$.

† To convert glucose in $\mathrm{mg} / \mathrm{dl}$ to $\mathrm{mmol} / \mathrm{l}$, multiply by 0.0555 . To convert cholesterol in $\mathrm{mg} / \mathrm{dl}$ to $\mathrm{mmol} / \mathrm{l}$, multiply by 0.0259 . To convert TAG in $\mathrm{mg} / \mathrm{dl}$ to $\mathrm{mmol} / \mathrm{l}$, multiply by 0.0113 . To convert energy in kcal to kJ, multiply by $4 \cdot 184$. 
respectively. Of the participants, $74 \%$ considered brown rice to be healthy. Intra-class correlations ranged from 0.40 for HOMAIR to 0.98 for body weight.

\section{Intervention effect}

During the intervention, no significant between-group differences were observed for markers of glycaemic control or lipids (Table 2). However, non-significant trends in decreased levels of fasting blood glucose, insulin, HbA1c, HOMA-IR, TAG, total cholesterol and LDL-cholesterol were observed for the brown rice diet compared with the white rice diet. Our secondary outcome, hs-CRP increased less in the brown rice diet (0.03 (sD 2.12) $\mathrm{mg} / \mathrm{l})$ compared with the white rice $\operatorname{diet}(0.63(\mathrm{sD} 2 \cdot 35) \mathrm{mg} / \mathrm{l})(P=0 \cdot 04)$. No significant between-group differences were observed for anthropometric measures, although non-significant trends in increased body weight, BMI, and percentage body fat were observed for the brown rice diet compared with the white rice diet. Among participants with the metabolic syndrome at baseline, there was a reduction in HbA1c during the brown rice diet relative to the white rice $\operatorname{diet}(-0 \cdot 18$ (SE $0 \cdot 08), P=0 \cdot 03$ ) while no difference in HbA1c was observed between diets among participants who did not have the metabolic syndrome (0.05 (SE 0.05), $P=0 \cdot 26)$ ( $P$-for-heterogeneity $=0.02$ ) (Table 3). No other statistically significant between-group differences were observed by metabolic syndrome status in study outcomes. The difference

Table 2. Changes in intervention outcomes from baseline between white rice (WR) and brown rice (BR) diets (Mean values and standard deviations; mean values with their standard errors)

\begin{tabular}{|c|c|c|c|c|c|c|c|c|c|c|c|c|}
\hline & \multicolumn{8}{|c|}{ Within-group difference } & \multirow{2}{*}{\multicolumn{4}{|c|}{$\begin{array}{c}\text { Between-group difference: } \\
\text { BR } v \text {. WR }\end{array}$}} \\
\hline & \multicolumn{4}{|c|}{ WR diet } & \multicolumn{4}{|c|}{ BR diet } & & & & \\
\hline & Mean & SD & $n$ & $P$ & Mean & SD & $n$ & $P$ & Mean & SE & $n$ & $P$ \\
\hline Body weight (kg) & -0.24 & $2 \cdot 2$ & 117 & 0.23 & -0.03 & 1.6 & 117 & 0.84 & 0.24 & $0 \cdot 26$ & 107 & 0.39 \\
\hline BMI $\left(\mathrm{kg} / \mathrm{m}^{2}\right)$ & -0.13 & 1.00 & 117 & $0 \cdot 16$ & -0.03 & 0.64 & 117 & 0.57 & 0.11 & $0 \cdot 12$ & 107 & 0.38 \\
\hline Body fat (\%) & -0.23 & $4 \cdot 28$ & 117 & 0.56 & 0.52 & 3.95 & 117 & $0 \cdot 16$ & 0.70 & 0.57 & 107 & 0.18 \\
\hline Waist circumference $(\mathrm{cm})$ & -0.06 & 3.9 & 117 & 0.87 & -0.06 & $3 \cdot 7$ & 117 & 0.86 & -0.01 & 0.55 & 107 & 1.0 \\
\hline Fasting blood glucose (mg/dl)* & 0.76 & $12 \cdot 4$ & 121 & 0.50 & 0.00 & $10 \cdot 6$ & 120 & $1 \cdot 0$ & -0.10 & $1 \cdot 72$ & 112 & 0.58 \\
\hline Fasting insulin $(\mu \mathrm{lU} / \mathrm{ml})$ & 0.90 & $9 \cdot 37$ & 121 & 0.29 & 0.36 & $8 \cdot 13$ & 120 & 0.63 & -0.61 & $1 \cdot 15$ & 112 & 0.62 \\
\hline $\mathrm{HbA} 1 \mathrm{c}(\mathrm{mmol} / \mathrm{mol})$ & -0.11 & $4 \cdot 15$ & 121 & 0.83 & -0.44 & 2.95 & 120 & $0 \cdot 10$ & -0.44 & 0.55 & 112 & 0.46 \\
\hline $\mathrm{HbA1c}(\%)$ & -0.01 & 0.38 & 121 & 0.83 & -0.04 & $0 \cdot 27$ & 120 & $0 \cdot 10$ & -0.04 & 0.05 & 112 & 0.46 \\
\hline Insulin resistance (HOMA-IR) & 0.30 & 2.66 & 121 & 0.22 & 0.11 & $2 \cdot 28$ & 120 & 0.61 & -0.20 & 0.33 & 112 & 0.54 \\
\hline TAG $(\mathrm{mg} / \mathrm{dl})^{*}$ & $-10 \cdot 3$ & $59 \cdot 3$ & 121 & 0.06 & -11.0 & $79 \cdot 8$ & 120 & 0.14 & -2.08 & 8.48 & 112 & 0.91 \\
\hline Cholesterol (mg/dl)* & 0.45 & $24 \cdot 8$ & 121 & 0.84 & $-2 \cdot 38$ & $26 \cdot 3$ & 120 & 0.32 & -2.67 & $3 \cdot 86$ & 112 & 0.43 \\
\hline HDL-cholesterol $(\mathrm{mg} / \mathrm{dl})^{*}$ & 0.28 & $4 \cdot 61$ & 121 & 0.50 & 0.42 & 4.56 & 120 & 0.32 & -0.07 & 0.62 & 112 & 0.80 \\
\hline LDL-cholesterol (mg/dl)* & 1.91 & 23.5 & 118 & 0.38 & $-1 \cdot 15$ & $24 \cdot 0$ & 116 & 0.61 & -2.65 & $3 \cdot 70$ & 108 & 0.36 \\
\hline hs-CRP (mg/l) & 0.63 & $2 \cdot 35$ & 121 & 0.004 & 0.03 & $2 \cdot 12$ & 120 & 0.86 & -0.46 & 0.28 & 112 & 0.04 \\
\hline
\end{tabular}

$\mathrm{HbA1c}$, glycated $\mathrm{Hb}$; HOMA-IR, homeostasis model assessment of insulin resistance; hs-CRP, high-sensitivity C-reactive protein.

* To convert glucose in $\mathrm{mg} / \mathrm{dl}$ to $\mathrm{mmol} / \mathrm{l}$, multiply by 0.0555 . To convert TAG in $\mathrm{mg} / \mathrm{dl}$ to $\mathrm{mmol} / \mathrm{l}$, multiply by 0.0113 . To convert cholesterol in mg/dl to mmol/l, multiply by 0.0259 .

Table 3. Between-group difference in changes in intervention outcomes between white rice (WR) and brown rice (BR) diets by baseline metabolic syndrome status*

(Mean values with their standard errors)

\begin{tabular}{|c|c|c|c|c|c|c|c|c|c|}
\hline & \multicolumn{4}{|c|}{ With metabolic syndrome: BR $v$. WR } & \multicolumn{4}{|c|}{ Without metabolic syndrome: BR $v$. WR } & \multirow[b]{2}{*}{$P$ for heterogeneity } \\
\hline & Mean & SE & $n$ & $P$ & Mean & SE & $n$ & $P$ & \\
\hline Body weight (kg) & $-0 \cdot 10$ & 0.37 & 43 & 0.91 & 0.46 & 0.35 & 64 & 0.23 & 0.39 \\
\hline BMI $\left(\mathrm{kg} / \mathrm{m}^{2}\right)$ & 0.04 & $0 \cdot 15$ & 43 & 0.73 & $0 \cdot 16$ & 0.17 & 64 & 0.42 & 0.73 \\
\hline Body fat (\%) & $1 \cdot 25$ & 0.94 & 43 & $0 \cdot 10$ & 0.32 & 0.72 & 64 & 0.69 & 0.29 \\
\hline Waist circumference $(\mathrm{cm})$ & 0.01 & 0.62 & 43 & 0.95 & -0.02 & 0.83 & 64 & 0.97 & 0.94 \\
\hline Fasting blood glucose $(\mathrm{mg} / \mathrm{dl}) \dagger$ & -2.70 & 2.62 & 44 & 0.12 & 1.59 & $2 \cdot 25$ & 68 & 0.54 & 0.10 \\
\hline Fasting insulin $(\mu \mathrm{IU} / \mathrm{ml})$ & 0.97 & $1 \cdot 79$ & 44 & 0.51 & -1.63 & 1.49 & 68 & 0.23 & 0.20 \\
\hline $\mathrm{HbA1c}(\mathrm{mmol} / \mathrm{mol})$ & -1.97 & 0.87 & 44 & 0.03 & 0.55 & 0.55 & 68 & 0.26 & 0.02 \\
\hline $\mathrm{HbA1c}(\%)$ & $-0 \cdot 18$ & 0.08 & 44 & 0.03 & 0.05 & 0.05 & 68 & 0.26 & 0.02 \\
\hline Insulin resistance (HOMA-IR) & 0.17 & 0.51 & 44 & 0.72 & -0.44 & 0.43 & 68 & 0.27 & 0.33 \\
\hline TAG (mg/dl)† & $-1 \cdot 84$ & $17 \cdot 43$ & 44 & 0.98 & $-2 \cdot 24$ & 8.35 & 68 & 0.86 & 0.91 \\
\hline Cholesterol $(\mathrm{mg} / \mathrm{dl}) \dagger$ & $-11 \cdot 27$ & 6.43 & 44 & 0.11 & 2.90 & 4.73 & 68 & 0.73 & 0.14 \\
\hline HDL-cholesterol (mg/dl)† & -1.07 & 0.97 & 44 & 0.69 & 0.57 & 0.80 & 68 & 0.50 & 0.45 \\
\hline LDL-cholesterol (mg/dl)† & -11.54 & $6 \cdot 89$ & 44 & 0.08 & $2 \cdot 79$ & $4 \cdot 11$ & 67 & 0.64 & 0.08 \\
\hline hs-CRP (mg/l) & -0.83 & 0.46 & 44 & 0.02 & -0.22 & 0.36 & 68 & 0.42 & 0.19 \\
\hline
\end{tabular}

$\mathrm{HbA1c}$, glycated $\mathrm{Hb}$; HOMA-IR, homeostasis model assessment of insulin resistance; hs-CRP, high-sensitivity C-reactive protein.

* The metabolic syndrome is defined as having at least three of the following: elevated waist circumference ( $\geq 90 \mathrm{~cm}$ in men, $\geq 80 \mathrm{~cm}$ in women); low $\mathrm{HDL}$-cholesterol ( $<40 \mathrm{mg} / \mathrm{dl}$ $(1.0 \mathrm{mmol} / \mathrm{l})$ in men, $<50 \mathrm{mg} / \mathrm{dl}(1.3 \mathrm{mmol} / \mathrm{l})$ in women); high TAG ( $\geq 150 \mathrm{mg} / \mathrm{dl} ; 1.7 \mathrm{mmol} / \mathrm{l})$; elevated blood pressure (systolic $\geq 130 \mathrm{or}$ diastolic $\geq 85 \mathrm{mmHg})$ and impaired fasting glucose $(\geq 100 \mathrm{mg} / \mathrm{dl} ; 5.6 \mathrm{mmol} / \mathrm{l})$.

† To convert glucose in $\mathrm{mg} / \mathrm{dl}$ to $\mathrm{mmol} / \mathrm{l}$, multiply by 0.0555 . To convert TAG in $\mathrm{mg} / \mathrm{dl}$ to $\mathrm{mmol} / \mathrm{l}$, multiply by 0.0113 . To convert cholesterol in $\mathrm{mg} / \mathrm{dl}$ to $\mathrm{mmol} / \mathrm{l}$, multiply by 0.0259 . 
between the brown rice and white rice groups was not statistically significant based on the multiple outcome of $1 \mathrm{df}$ test including primary and secondary outcomes as one composite outcome $(P=0 \cdot 09)$.

Between-group changes in study outcomes did not differ significantly by sex, age or baseline physical activity level ( $P$ for-heterogeneity $\geq 0.05$ ) (Supplementary Table S1). For participants who had a BMI $\geq 25 \mathrm{~kg} / \mathrm{m}^{2}$ at baseline, there was a suggestion of a benefit of brown rice relative to white rice on $\mathrm{HbA} 1 \mathrm{c}$, total cholesterol and LDL-cholesterol compared with participants with a BMI $<25 \mathrm{~kg} / \mathrm{m}^{2}$ ( $P$-for-heterogeneity $\left.<0.05\right)$. For participants without prediabetes, there was a suggestion of a benefit of brown rice relative to white rice on HDL-cholesterol compared with participants with prediabetes ( $P$-for-heterogeneity $=0.04$ ); however, this could be due to chance. Among participants who thought brown rice was healthy, the brown rice group gained more weight than the white rice group, while among participants who did not think brown rice was healthy, there was no difference in weight change between groups $(P$ for-heterogeneity $=0 \cdot 002$ ). Changes in HbA1c were more favourable in the brown rice group among those who did not think brown rice was healthy while there was no difference among those who thought brown rice was healthy ( $P$-for-hetero geneity $=0 \cdot 01$ ) (Supplementary Fig. S1). There was no evidence of a carry-over effect between rice periods for the primary outcomes and adjusting the analysis for change in BMI did not alter results (data not shown). Results were also unchanged when end of follow-up measurements only were used to assess betweengroup differences (data not shown).

\section{Differences in dietary intake and satiety}

Based on data from repeated 24-h dietary recalls throughout the intervention, the brown rice group had a lower GI and a significant decrease in intake of refined grains and percentage of energy from carbohydrate and significant increase in intake of whole grains, fibre and percentage of energy from total and saturated fat compared with the white rice group (Table 4). The brown rice group also showed a trend towards a suggestive increase in intake of percentage of energy from protein, which, may be due to the higher protein content of brown rice compared with white rice. Based on mean ratings from a Likert scale administered monthly, the brown rice group reported feeling more satiated from intervention meals than the white rice group throughout the study; however, the difference in satiety was statistically significant only during the second month of the trial (Supplementary Table S2).

\section{Adherence}

According to direct observation by study staff during intervention meals, participant attendance, which was recorded in a register in the dining area, in both groups was moderate with an average participation rate of $61.2 \%$ during the brown rice period and $64.5 \%$ during the white rice period. Mean consumption of rice from intervention meals as measured by number of spoons served per participant was $182 \mathrm{~g}$ during the brown rice period and $175 \mathrm{~g}$ during the white rice period. This was supported by data from 24-h diet recalls, which showed that the brown rice group had an increased intake of fibre compared with the white rice group over the course of the study (Table 4).

\section{Discussion}

In this 3-month cross-over trial, which enrolled healthy overweight and obese adults in urban South India, replacing parboiled brown rice for white rice did not significantly improve markers of glycaemic control or lipid parameters. However,

Table 4. Differences in dietary intake between white rice (WR) and brown rice (BR) diets from baseline to end of follow-up (Mean values and standard deviations; mean values and $95 \%$ confidence intervals)

\begin{tabular}{|c|c|c|c|c|c|c|c|}
\hline & \multicolumn{2}{|c|}{ Changes in WR diet } & \multicolumn{2}{|c|}{ Changes in BR diet } & \multicolumn{2}{|c|}{ Difference in changes } & \multirow[b]{2}{*}{$P$} \\
\hline & Mean & SD & Mean & SD & Mean & $95 \% \mathrm{Cl}$ & \\
\hline White rice $(g / d)$ & $13 \cdot 3$ & $90 \cdot 3$ & $-20 \cdot 0$ & $98 \cdot 2$ & -32.5 & $-54 \cdot 3,-10 \cdot 8$ & 0.004 \\
\hline Refined grains (g/d) & $16 \cdot 7$ & $102 \cdot 4$ & $-17 \cdot 9$ & $124 \cdot 0$ & $-35 \cdot 0$ & $-63 \cdot 8,-6 \cdot 2$ & 0.02 \\
\hline Whole grains $(\mathrm{g} / \mathrm{d})$ & -4.5 & $62 \cdot 1$ & $20 \cdot 2$ & $127 \cdot 5$ & 24.7 & $0.48,48.8$ & 0.05 \\
\hline Fruit (g/d) & $-18 \cdot 8$ & $106 \cdot 6$ & $-1 \cdot 7$ & $127 \cdot 8$ & $16 \cdot 6$ & $-11 \cdot 2,44 \cdot 4$ & 0.24 \\
\hline Leafy green vegetables $(\mathrm{g} / \mathrm{d})$ & $2 \cdot 2$ & $19 \cdot 9$ & 1.8 & $28 \cdot 1$ & -0.06 & $-5 \cdot 5,5.4$ & 0.98 \\
\hline Other vegetables $(\mathrm{g} / \mathrm{d})$ & $1 \cdot 8$ & $31 \cdot 6$ & $3 \cdot 1$ & $39 \cdot 2$ & $1 \cdot 2$ & $-8 \cdot 1,10.5$ & 0.79 \\
\hline Root vegetables $(\mathrm{g} / \mathrm{d})$ & 8.0 & 62.5 & $11 \cdot 3$ & 61.6 & $3 \cdot 3$ & $-11 \cdot 8,18 \cdot 4$ & 0.66 \\
\hline Tubers $(\mathrm{g} / \mathrm{d})$ & 10.9 & $48 \cdot 8$ & $17 \cdot 7$ & $47 \cdot 7$ & $6 \cdot 7$ & $-7 \cdot 8,21 \cdot 3$ & 0.36 \\
\hline Legumes (g/d) & $-9 \cdot 0$ & $57 \cdot 3$ & $-1 \cdot 8$ & $57 \cdot 9$ & $7 \cdot 2$ & $-4.9,19 \cdot 2$ & 0.24 \\
\hline Poultry (g/d) & $-93 \cdot 1$ & 167.5 & $16 \cdot 4$ & 96.9 & $110 \cdot 6$ & $-130 \cdot 7,351.9$ & 0.19 \\
\hline Dairy products (g/d) & $-18 \cdot 4$ & 243.5 & 4.9 & $140 \cdot 3$ & $16 \cdot 7$ & $-25 \cdot 4,58 \cdot 9$ & 0.43 \\
\hline Added sugar (g/d) & -3.0 & $22 \cdot 4$ & $-1 \cdot 6$ & $17 \cdot 1$ & $1 \cdot 3$ & $-3 \cdot 6,6 \cdot 2$ & 0.60 \\
\hline Edible oils (g/d) & -4.5 & 23.5 & $2 \cdot 2$ & $21 \cdot 7$ & $6 \cdot 7$ & $1 \cdot 1,12 \cdot 3$ & 0.02 \\
\hline Dietary fibre $(\mathrm{g} / \mathrm{d})$ & $-2 \cdot 1$ & $14 \cdot 8$ & 3.0 & $16 \cdot 9$ & $5 \cdot 1$ & $1 \cdot 5,8 \cdot 7$ & 0.01 \\
\hline Glycaemic index & 2.9 & $6 \cdot 4$ & 0.12 & 7.5 & $-2 \cdot 7$ & $-4 \cdot 3,-1 \cdot 1$ & 0.001 \\
\hline Glycaemic load & $7 \cdot 0$ & $62 \cdot 3$ & $1 \cdot 3$ & $51 \cdot 8$ & $-5 \cdot 6$ & $-19 \cdot 1,7.9$ & 0.41 \\
\hline Total energy $(\mathrm{kcal} / \mathrm{d})^{*}$ & -105.9 & $736 \cdot 1$ & $15 \cdot 8$ & $690 \cdot 0$ & $121 \cdot 8$ & $-48 \cdot 8,292 \cdot 3$ & 0.16 \\
\hline Carbohydrate (\% energy) & $3 \cdot 1$ & $9 \cdot 0$ & -0.25 & $9 \cdot 0$ & -3.4 & $-5 \cdot 6,-1 \cdot 2$ & 0.003 \\
\hline Protein (\% energy) & -0.83 & 3.7 & -0.01 & 3.5 & 0.83 & $-0.07,1.7$ & 0.07 \\
\hline Total fat (\% energy) & $-2 \cdot 3$ & $7 \cdot 8$ & 0.20 & $7 \cdot 5$ & $2 \cdot 5$ & $0.71,4.4$ & 0.01 \\
\hline Saturated fat (\% energy) & $-1 \cdot 4$ & $4 \cdot 0$ & -0.37 & 3.9 & 0.99 & $0.02,2.0$ & 0.04 \\
\hline Monounsaturated fat (\% energy) & $-1 \cdot 1$ & $3 \cdot 1$ & -0.41 & $3 \cdot 2$ & 0.67 & $-0.11,1.4$ & 0.09 \\
\hline Polyunsaturated fat (\% energy) & -0.07 & 3.5 & 0.70 & $3 \cdot 9$ & 0.76 & $-0.1,1 \cdot 7$ & 0.10 \\
\hline
\end{tabular}

* To convert energy in kcal to kJ, multiply by $4 \cdot 184$. 
beneficial trends were observed for brown rice on most markers and a slight benefit on hs-CRP was observed in the brown rice compared with the white rice group. Of note, a benefit of brown rice was observed on HbA1c among participants with the metabolic syndrome and among those with a BMI $\geq 25 \mathrm{~kg} / \mathrm{m}^{2}$ at baseline, which may be clinically significant depending on baseline HbA1c level. These sub-group findings support our previous short-term trial, which found that replacing white rice with brown rice for $5 \mathrm{~d}$ in a similar South Indian population significantly reduced the 24-h glycaemic response and fasting insulinaemic response ${ }^{(7)}$. Findings from two small trials in Japan ${ }^{(19)}$ and Vietnam ${ }^{(20)}$ also provide evidence for beneficial effects of replacing white rice with pregerminated brown rice on blood glucose and lipid concentrations. In addition, a recent 8-week clinical study of glutinous brown rice showed a significant reduction in HbA1c among patients with $\mathrm{T} 2 \mathrm{D}^{(21)}$. These findings are consistent with prospective cohort studies in Western and Asian populations that have reported positive associations between intake of white rice and risk of $\mathrm{T} 2 \mathrm{D}^{(5)}$ and our analysis that showed an inverse association between substituting brown rice for white rice on $\mathrm{T} 2 \mathrm{D}$ risk $^{(6)}$.

The observed benefit of brown rice among those with the metabolic syndrome and who were overweight is where we would expect to see greatest benefit, since these groups have more room for improvement and may be more susceptible to the adverse effects of white rice. For a healthy weight population without the metabolic syndrome, the benefit of replacing white rice with brown rice may only be seen in a longer trial to assess prevention of weight gain or the metabolic syndrome, which would be logistically difficult to implement. We did not observe benefits of brown rice among participants with prediabetes, but some trends were noted, which may have reached statistical significance with a larger sample size or longer duration. Given the design of the present study, individuals with the metabolic syndrome would, in theory, be the right target and benefits of brown rice in this group may be helpful in decreasing the progression to $\mathrm{T} 2 \mathrm{D}$.

During the trial, the white rice group unexpectantly experienced slight reductions in body weight, BMI, percentage body fat and TAG, although differences were not statistically significant. This suggests the possibility of diminished statistical power to detect between-group differences owing to favourable changes in these risk factors in the control group. However, it is not clear what may have motivated these changes. Based on 24-h recall data collected throughout the trial, the white rice group decreased their intake of energy while the brown rice group increased their energy intake, although the betweengroup difference was not significant. The brown rice group also increased intake of total and saturated fat and edible oils relative to the white rice group, which could adversely impact body weight and cardiometabolic risk. However, the magnitude of this risk is unclear given that the brown rice group also improved healthful aspects of the diet such as increased intake of fibre. We also observed that among participants who thought brown rice was healthy, the brown rice group gained more weight and percentage body fat than the white rice group. Based on this finding, we can speculate that the brown rice group may have rationalised their intake of more energy. Since awareness and availability of brown rice was low at the time of the study, we needed to impart knowledge about brown rice to encourage volunteers to participate. The knowledge about the health benefits of brown rice in the setting of an open label, ad libitum trial to better reflect real life may have influenced eating behaviours. Since blinding was not possible, we assessed the effect of the intervention under a 'real world' clinical setting and evaluated intervention delivery rather than efficacy ${ }^{(22)}$. In studies where blinding is not possible, design strategies such as adjustments in sample size calculations should be considered to reduce the potential effects of unintended behaviours.

The main difference between brown rice and white rice is in the method of processing, during which the majority of the bran and some of the germ are removed ${ }^{(23)}$. These parts of the grain contain numerous phytochemicals including polyphenols, phytosterols, and lignans, as well as vitamins, minerals, essential fatty acids and fibre, many of which may confer protection against T2D and CVD risk ${ }^{(23)}$. Brown rice contains nearly exclusively insoluble cereal fibre, which has been consistently associated with improved insulin sensitivity and reduced risk for T2D in experimental and observational studies ${ }^{(24,25)}$. Insoluble fibre may also improve satiety ${ }^{(26)}$, which is supported by our finding of greater satiety ratings during the brown rice period compared with the white rice period. Of note, baseline intake of dietary fibre was already high in our study population (almost double that of most national averages), which may impact the generalisability of our findings. Those with lower intakes of fibre may benefit more from replacing refined grains with whole grains in the diet. In addition, compared with brown rice other whole grains have higher fibre content and different attributes, which when considered alongside the high baseline fibre intake of participants, our findings may not be representative of replacing refined grains with whole grains in general.

Diets high in cereal fibre have also been linked to a low GI and glycaemic load (GL), due to slower digestion and absorption of glucose into the circulation. Low-GI and -GL diets have been associated with reduced cardiometabolic risk in prospective cohort studies $^{(27,28)}$. We found that any degree of polishing of parboiled brown rice leads to a higher glycaemic response for the same rice strain, suggesting a greater role of polishing than parboiling on $\mathrm{GI}^{(13)}$. The adverse effects of high-GI and -GL diets tend to be more evident in individuals with excess adiposity, who are generally more insulin-resistant than lean individuals ${ }^{(29)}$. This is consistent with our findings of benefits of brown rice on HbAlc among participants with the metabolic syndrome and improvements in HbA1c, cholesterol and LDL-cholesterol among participants with $B M I \geq 25 \mathrm{~kg} / \mathrm{m}^{2}$. The benefits of brown rice on cardiometabolic risk are likely due to the combination of having a low GI, high amounts of cereal fibre and the accompanying natural package of nutrients found in the intact grain. Moreover, brown rice and other whole grains are important contributors to overall diet quality ${ }^{(30)}$.

To the best of our knowledge, this is the first randomised intervention trial that has evaluated substituting a refined carbohydrate staple for a whole grain alternative on biomarkers of cardiometabolic risk in a population of adults at risk of developing T2D in urban South India. This study is of great relevance, given the high prevalence of $\mathrm{T} 2 \mathrm{D}$ in India and expected rates of 
increase over the next decade. Other strengths include the variety of intervention foods, standardised preparation and cooking methods and assessment of compliance measured by direct observation of study staff during intervention meals and by 24-h diet recalls throughout follow-up. A limitation of our study was loss of statistical power to detect between-group differences in primary outcomes due to potential behaviour changes in the white rice group. There was also a relatively high drop-out rate $(33 \%)$, mostly due to job relocation and small sample sizes for sub-group analyses. However, despite the loss of statistical power, the majority of our primary outcomes showed trends towards favourable changes in the brown rice compared with the white rice group, which may have reached statistical significance with a longer duration or if our target population was individuals with the metabolic syndrome. The duration of our study, although typical for dietary interventions, may have been insufficient to detect meaningful changes in clinical indices among a healthy population or it is possible that improving rice quality alone is not sufficient to lead to clinically meaningful changes in metabolic biomarkers in an overall healthy population.

In conclusion, substituting parboiled brown rice for white rice for 3 months showed a potential benefit on glycaemia among participants with the metabolic syndrome and among those who had an elevated BMI. Effects of brown rice on changes in body weight and glycaemia also differed by perception of the health benefits of brown rice, highlighting the importance of health-related behaviours. Larger studies of longer duration that consider intervention effectiveness and overall diet quality are needed to examine the role of brown rice in the prevention of T2D in India, particularly among individuals with the metabolic syndrome.

\section{Supplementary material}

To view supplementary material for this article, please visit https://doi.org/10.1017/S000711451900076X

\section{Acknowledgements}

We would like to thank our colleagues in the Global Nutrition and Epidemiologic Transition (GNET) Initiative at the Harvard T.H. Chan School of Public Health and collaborating institutions for their support on this project.

This work was funded by the Fogarty International Center at the National Institutes of Health (R03TW008726). On behalf of Dr. Mohan and colleagues, we disclose that brown rice and a new high-fibre white rice is currently being marketed at Dr. Mohan's Diabetes Specialities Centre.

V. M., F. B. H. and D. S. designed the research. V. S., M. R. B., P. V., N. L., R. G., A. K. and K. K. conducted the research and coordinated the study centre. D. S., B. H. and R. L. analysed the data. V. S., N. M. W., R. M. A., W. C. W., D. S., C. J., F. B. H., K. K. and V. M. contributed to data interpretation and provided critical revisions on the manuscript. V. S. M. contributed to data interpretation, wrote the manuscript and constructed the tables and figures. F. B. H. and V. M. had primary responsibility for the final content. All authors read and approved the final manuscript.

The authors declare that there are no conflicts of interest.

\section{References}

1. International Diabetes Federation (2017) IDF Diabetes Atlas, 8th ed. Brussels, Belgium: International Diabetes Federation.

2. Anjana RM, Deepa M, Pradeepa R, et al. (2017) Prevalence of diabetes and prediabetes in 15 states of India: results from the ICMR-INDIAB population-based cross-sectional study. Lancet Diabetes Endocrinol 5, 585-596.

3. Malik VS, Willett WC \& Hu FB (2013) Global obesity: trends, risk factors and policy implications. Nat Rev Endocrinol 9, 13-27.

4. Radhika G, Van Dam RM, Sudha V, et al. (2009) Refined grain consumption and the metabolic syndrome in urban Asian Indians (Chennai Urban Rural Epidemiology Study 57). Metabolism 58, 675-681.

5. Hu EA, Pan A, Malik V, et al. (2012) White rice consumption and risk of type 2 diabetes: meta-analysis and systematic review. BMJ 344, e1454.

6. Sun Q, Spiegelman D, van Dam RM, et al. (2010) White rice, brown rice, and risk of type 2 diabetes in US men and women. Arch Intern Med 170, 961-969.

7. Mohan V, Spiegelman D, Sudha V, et al. (2014) Effect of brown rice, white rice, and brown rice with legumes on blood glucose and insulin responses in overweight Asian Indians: a randomized controlled trial. Diabetes Technol Ther 16, 317-325.

8. Sudha V, Spiegelman D, Hong B, et al. (2013) Consumer Acceptance and Preference Study [CAPS] on brown and undermilled Indian rice varieties in Chennai, India. J Am Coll Nutr 32 , 50-57.

9. Kumar S, Mohanraj R, Sudha V, et al. (2011) Perceptions about varieties of brown rice: a qualitative study from Southern India. J Am Diet Assoc 111, 1517-1522.

10. Shobana S, Malleshi NG, Sudha V, et al. (2011) Nutritional and sensory profile of two Indian rice varieties with different degrees of polishing. Int J Food Sci Nutr 62, 800-810.

11. Mattei J, Malik V, Wedick NM, et al. (2015) Reducing the global burden of type 2 diabetes by improving the quality of staple foods: The Global Nutrition and Epidemiologic Transition Initiative. Global Health 11, 23.

12. Wedick NM, Sudha V, Spiegelman D, et al. (2015) Study design and methods for a randomized crossover trial substituting brown rice for white rice on diabetes risk factors in India. Int J Food Sci Nutr 66, 797-804.

13. Shanmugam S, Nagarajan L, Mookambika RB, et al. (2017) Even minimal polishing of an Indian parboiled brown rice variety leads to increased glycemic responses. Asia Pac J Clin Nutr 26, 829-836.

14. Matthews DR, Hosker JP, Rudenski AS, et al. (1985) Homeostasis model assessment: insulin resistance and beta-cell function from fasting plasma glucose and insulin concentrations in man. Diabetologia 28, 412-419.

15. World Health Organization (2000) The Asia Pacific Perspective. Redefining Obesity and its Treatment. Melbourne: International Diabetes Institute for the International Association for the Study of Obesity and International Obesity Task Force.

16. Anjana RM, Sudha V, Lakshmipriya N, et al. (2015) Reliability and validity of a new physical activity questionnaire for India. Int J Behav Nutr Phys Act 12, 40.

17. Fitzmaurice GM, Laird NM \& Ware JH (2004) Applied Longitudinal Analysis. Hoboken, NJ: John Wiley \& Sons, Inc.

18. Pocock SJ, Geller NL \& Tsiatis AA (1987) The analysis of multiple endpoints in clinical trials. Biometrics 43, 487-498. 
19. Hsu TF, Kise M, Wang MF, et al. (2008) Effects of pregerminated brown rice on blood glucose and lipid levels in free-living patients with impaired fasting glucose or type 2 diabetes. J Nutr Sci Vitaminol (Tokyo) 54, 163-168.

20. Bui TN, Le TH, Nguyen do H, et al. (2014) Pre-germinated brown rice reduced both blood glucose concentration and body weight in Vietnamese women with impaired glucose tolerance. J Nutr Sci Vitaminol (Tokyo) 60, 183-187.

21. Nakayama T, Nagai Y, Uehara Y, et al. (2017) Eating glutinous brown rice twice a day for 8 weeks improves glycemic control in Japanese patients with diabetes mellitus. Nutr Diabetes 7, e273.

22. Satija A, Yu E, Willett WC, et al. (2015) Understanding nutritional epidemiology and its role in policy. Adv Nutr 6, 5-18.

23. Slavin JL, Martini MC, Jacobs DR, Jr., et al. (1999) Plausible mechanisms for the protectiveness of whole grains. Am J Clin Nutr 70, 459S-463S

24. InterAct Consortium (2015) Dietary fibre and incidence of type 2 diabetes in eight European countries: the EPIC-InterAct Study and a meta-analysis of prospective studies. Diabetologia $\mathbf{5 8}$, 1394-1408.
25. Weickert MO \& Pfeiffer AF (2008) Metabolic effects of dietary fiber consumption and prevention of diabetes. J Nutr 138, 439-442.

26. Clark MJ \& Slavin JL (2013) The effect of fiber on satiety and food intake: a systematic review. J Am Coll Nutr 32, 200-211.

27. Atkinson FS, Foster-Powell K \& Brand-Miller JC (2008) International tables of glycemic index and glycemic load values: 2008. Diabetes Care 31, 2281-2283.

28. Bhupathiraju SN, Tobias DK, Malik VS, et al. (2014) Glycemic index, glycemic load, and risk of type 2 diabetes: results from 3 large US cohorts and an updated meta-analysis. Am J Clin Nutr 100, 218-232.

29. Ding EL \& Malik VS (2008) Convergence of obesity and high glycemic diet on compounding diabetes and cardiovascular risks in modernizing China: an emerging public health dilemma. Global Health $\mathbf{4}, 4$.

30. US Department of Health and Human Services and US Department of Agriculture (2015) Dietary Guidelines for Americans, 2015-2020, 8th ed. http://health.gov/dietary guidelines/2015/guidelines/ 